\section{International Journal of Karamanoglu Mehmetbey Educational Research}

ULUSLARARASI

KARAMANOĞLU MEHMETBEY EĞITIM ARAŞTIRMALARI DERGISİ

Cilt 3 - Özel Sayı 1 Eylül 2021

Kitap İncelemesi

\title{
Kitap Tanıtımı: 21. Yüzyıl Becerileri ve Türkçe Eğitimi
}

\section{Book Introduction: 21st Century Skills and Turkish Education}

Büşra Gociaoğlu*1

Karamanoğlu Mehmetbey
Uluslararası Eğitim
Araştırmaları Dergisi
Eylül, 2021
Cilt 3, Özel Sayı 1
Sayfalar: 50-54
http://dergipark.gov.tr/ukmead
*Sorumlu Yazar
DOI: 10.47770/ukmead.983292

Halil Erdem Çocuk ve Taşkın Soysal, 21. Yüzyıl Becerileri ve Türkçe Eğitimi, Ankara: Nobel Akademik Yayıncılık, 2021, 260 sayfa, ISBN: 978-625-439-388-4

21. yüzyılda bireylerin akademik, sosyal ve mesleki yaşamlarında aktif olarak var olabilmeleri için birtakım becerilere ve yetkinliklere sahip olmaları gerekmektedir. 21. yüzyll becerileri de bu temel ihtiyacın bir sonucu olarak ortaya çıkmıştır. Voogt ve Roblin (2010)'e göre 21. yüzyıl becerileri bilgi toplumuna katkıda bulunabilmek için bireylerin ihtiyaç duyduğu bilgi ve becerilerin genel adıdır. P21 (2019)' e göre ise 21. yüzyıl becerileri bireylerin iş ve yaşamda başarılı olabilmeleri için gerekli beceri, bilgi ve uzmanlıklar olarak tanımlanmıştır.

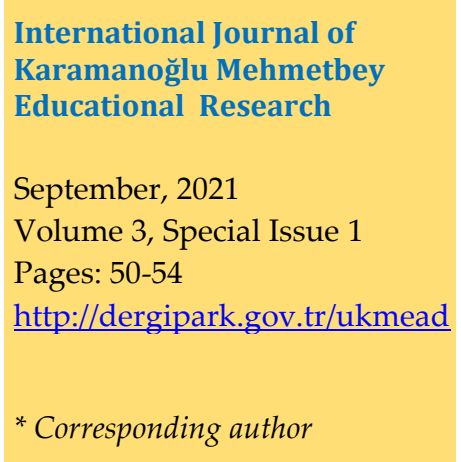

International Journal of Karamanoğlu Mehmetbey Educational Research September, 2021 Volume 3, Special Issue 1 Pages: 50-54 http://dergipark.gov.tr/ukmead * Corresponding author DOI:10.47770/ukmead.983292

Dijital çağ olarak da adlandırılan 21. yüzyıl hayatın her alanının teknolojiyle donatıldığı, değişim ve dönüşümün daha önce hiç olmadığı kadar hızla gerçekleştiği bir yüzyıl olarak karşımıza çıkmaktadır. Bu değiş̧imi hem etkileyen hem de bu değiş̧imden etkilenen bir süreç olarak eğitim, bireyin ve toplumun ihtiyaçlarına göre şekillenir. Geleceğin taleplerine dönük bireyler yetiştirmeyi, bir başka deyişle, toplumları geleceğe hazırlamayı amaçlar. 21. yüzyıl odaklı eğitim-öğretim yaklaşımı da günümüzün ve geleceğin taleplerini yansıtan, bireylerin sosyal ve mesleki alanlarda yaşam kalitesini arttırmaya yönelik becerileri kapsar. Bu yönüyle 21. yüzyıl becerileri eğitimin öncelikli hedefi hâline gelmiştir. Bu doğrultuda bazı devletler çeşitli kurum ve kuruluşlar aracılığıla eğitim politikalarını çağın gereklerine uygun olarak yenilemiş, ö̆retim programlarını 21. yüzyıl becerilerini kapsayacak nitelikte güncellemiştir. Ülkemizde de bu becerilere uygun olarak Türkiye Yeterlilikler Çerçevesi (TYÇ) kapsamında sekiz anahtar yetkinlik belirlenmiş; mevcut eğitim sisteminin belirlenen bu yetkinliklerde bütünleşmiş bilgi, beceri ve davranışlara sahip karakterde bireyler yetiştirmeyi amaçladığı belirtilmiştir (MEB, 2019).

Ana dili eğitimi temelde dil ve düşünme becerilerinin geliştirilmesine yönelik bir süreçtir; dil becerilerinin yanı sıra problem çözme, yaratıcı ve eleştirel düşünme gibi birçok temel ve üst düzey beceriyi kazandırmayı hedefler. Ural (2003)' a göre ana dili sadece düşünce hayatının değil, kültürel hayatın, hatta insanlar arası ilişkilerin ve sosyal hayatın gelişmesinde de oldukça önemlidir. Bu durum 21. yüzyıl becerilerinin geliştirilmesinde Türkçe derslerini oldukça işlevsel kılmaktadır. Türkçe Dersi Öğretim Programı; dil becerilerinin ve yeterliliklerinin geliştirilmesini, diğer tüm alanlarda öğrenme, kişisel ve sosyal gelişme

\footnotetext{
${ }^{1}$ Karamanoğlu Mehmetbey Üniversitesi, Eğitim Fakültesi, busragociaoglu@,kmu.edu.tr
} 
ile mesleki becerileri edinmenin ön şartı olarak kabul etmiştir (MEB, 2019). Bu yaklaşımla paralel olarak programın öğrenmeöğretme süreçlerinde 21. yüzyıl becerilerine yer verildiği açıç̧a görülmektedir.

Ana dili eğitimi son yıllarda artış gösteren çalışmalarla birlikte 21. yüzyıl becerilerinin geliştirilmesine yönelik uygulamalarda merkezî bir konuma yerleşmiştir. Bu çalışmalardan biri de 2021 yılında yayımlanan "21. Yüzyıl Becerileri ve Türkçe Eğitimi" başlıklı kitaptır. Yayın Nobel Akademi Yayıncılık tarafından çıkarılmıştır. Editörlügünü Dr. Halil Erdem Çocuk ve Dr. Taşkın Soysal'ın yapmış olduğu kitabın yazarları Prof. Dr. Faik Kanatll, Doç Dr. Mehmet Kurudayığlu, Doç. Dr. Esra Nur Tiryaki, Dr. Halil Erdem Çocuk, Dr. Taşkın Soysal, Dr. Gülşah Mete, Arş. Gör. Dr. Gürol Yokuş, Arş. Gör. Dr. Serkan Bayrakçı, Dr. Gülşat Bican, Dr. Alperen Yandı, Dr. Mutlu Uygur, Öğr. Gör. Ozan Korkmaz, Öğr. Gör. Yunus Emre Çekici, Dr. Haluk Güngör ve Arş. Gör. Büşra Gociaoğlu' dur. Adından da anlaşllacağı üzere 21. yüzyıl becerileri bağlamında Türkçe eğitimini konu alan yayın toplamda 12 bölümden oluşmaktadır. İlk altı bölümde kavramsal bir çerçeve oluşturması adına 21. yüzyıl becerilerinin tanımlanması ve sınıflandırılmasına yönelik bilgiler verilmiş, sonraki bölümlerde 21. yüzyıl becerileri ana dili olarak Türkçe eğitimi ve yabancı dil olarak Türkçe öğretimi bağlamında ele alınmıștır.

Birinci bölüm “21. yüzyll becerileri nelerdir?” sorusuna genel bir cevap niteliğindedir. Bu bölümde 21. yüzyll becerilerinin tanımlanması, iş hayatı ve günlük yaşam bağlamında öneminin kavranması kazanımları hedeflenmiştir. Bu amaçla 21. yüzyıl becerilerinden yola çıkarak günlük yaşam ve çalışma ortamında bireylerden beklenen tutum ve davranışlar belirtilmiştir. Mevcut gelişmelere uyum sağlamak ve geleceğe hazırlıklı olmak adına eğitimin, özellikle 21. yüzyıl becerileriyle bütünleştirilmiş müfredatların ve buna yönelik eğitim-öğretim tasarımlarının önemi vurgulanmıştır.

21. yüzyıl becerileri gerek günlük yaşamda gerek iş ve okul ortamında sağlıklı ilişkiler kurabilmek, başarılı ve verimli olabilmek adına bireylerin ihtiyaçlarından doğmuştur. Teknolojik gelişmelerle birlikte yaşamın her alanında hızla gerçekleşen değişim ve dönüşümler bu becerilerin sistematik bir biçimde eğitim-öğretim ortamlarına dâhil edilmesi gerektiğini göstermektedir. Bu sebeple çeşitli kurum ve kuruluşlar kavramsal çerçeveler oluşturarak 21. yüzyıl becerilerini tanımlamışlardır. Bölümde beceriler tanımlanırken literatürde sıklıkla vurgulandığı görülen 21. yüzyıl Öğrenme Ortaklığı (P21) Çerçevesi esas alınmıştır. 21. Yüzyıl Öğrenme Ortaklığı (P21) Çerçevesi; yaklaşımı, amacı ve vizyonlarıyla birlikte tanıtılmış, 21. yüzyıl becerileri bu çerçevede tanımlanmıştır. 21. Yüzyıl Öğrenme Ortaklığı (P21) Çerçevesi'nde 21. yüzyıl becerileri; "öğrenme ve yenilikçilik becerileri", "yaşam ve kariyer becerileri” ve "bilgi, medya ve teknoloji becerileri” olmak üzere üç beceri alanında ele alınmıștır. Söz konusu beceri alanlarında yer alan beceriler, bu becerilerin gerektirdiği alt beceriler ile birlikte açılanmıştır. 21. Yüzyıl Öğrenme Ortaklı̆̆ı (P21) Çerçevesi'nde yer alan beceriler aşağıdaki gibidir:

- Yaratıcılık ve yenilikçilik

- Eleştirel düşünme ve problem çözme

- İletişim

- İş birliği

- Esneklik ve uyum

- Girişimcilik ve öz yönetim

- Sosyal ve kültürlerarası beceriler

- Üretkenlik ve hesap verebilirlik

- Liderlik ve sorumluluk

- Bilgi okuryazarlı̆g

- Medya okuryazarlığı

- Bilgi ve iletişim teknolojileri (BİT) okuryazarlığı

İkinci bölümde 21. Yüzyıl Öğrenme Ortaklığı P(21) Çerçevesi'nin yanı sıra alan yazınında ön plana çıkan çeşitli çerçeveler tablolaştırılarak sunulmuş, çerçevelerin ortak ve farklı yönleri ortaya çıkarılarak çerçeveler arası karşılaştırmalı bir inceleme yapılmıştır. 21. yüzyıl becerileri çerçevelerinin tanıtılması, karşılaştırılması ve eğitim sistemi açısından değerlendirilmesi gibi kazanımlar hedeflenmiştir. 21. yüzyıl becerilerine yönelik hazırlanmış çerçevelerdeki bu çeșitlilik, becerilerin günümüz ve gelecek için değerini göstermektedir. Çerçevelerin benzer amaçlar doğrultusunda geliştirildiği ve içerdiği beceriler açısından tutarlılık gösterdiği, farklılıkların ise çerçevelerde odaklanılan beceri alanlarında ortaya çıktığı tespit edilmiştir. Bu bölümde sırasıyla aşağıdaki sekiz çerçeveye yer verilmiştir:

- Hayat Boyu Öğrenme için Avrupa Yeterlilikler Çerçevesi (AYÇ)

- Türkiye Yeterlilikler Çerçevesi (TYÇ)

- Ekonomik İş Birliği ve Kalkınma Örgütü (OECD) Beceriler Çerçevesi

- 21. Yüzyll Becerileri Ortaklığı (P21) Çerçevesi 
- 21. Yüzyll Becerilerinin Değerlendirilmesi ve Öğretilmesi (ATSC21) Çerçevesi

- Kuzey Merkez Bölgesi Eğitim Laboratuvarı (NCREL) “enGauge” Beceriler Çerçevesi,

- Amerikan Kolejleri ve Üniversiteler Birliği (AACU) Beceriler Çerçevesi

- Uluslararası Eğitimde Teknoloji Topluluğu (ISTE) Beceriler Çerçevesi

Üçüncü bölümde 21. Yüzyıl Öğrenme Ortaklığı (P21) Çerçevesinde yer alan yaşam ve kariyer becerileri ele alınmıştır. 21. yüzyıl yaşam ve kariyer becerileri tanımlanmış, becerilerin bireylerin eğitim ve kariyer süreci açısından önemine değinilmiştir. Günümüzde bireylerin gerek günlük yaşamlarında gerek çalışma ortamlarında sosyal ve duygusal olarak karşı karşıya kaldıkları karmaşık yapılar, kimi zaman başarısız olmalarına veya sağlıksız ilişkiler kurmalarına neden olabilmektedir. 21. yüzyıl beceri alanlarından yaşam ve kariyer becerileri bireylerin günlük yaşamlarında ve çalışma ortamlarında, bireysel ya da toplumsal ilişkilerinde başarılı bir süreç yürütebilmeleri için gerekli becerileri kapsamaktadır. Bu beceriler "esneklik ve uyum", "girişimcilik ve öz yönetim", "sosyal ve kültürlerarası beceriler", "verimlilik ve hesap verebilirlik" ve "liderlik ve sorumluluk" becerileri olarak belirlenmiştir. Her bir beceri kapsamlı bir şekilde ele alınmış, çalışma ve öğrenme ortamları için önemi vurgulanmıştır.

Dördüncü bölümde 21. Yüzyll Öğrenme Ortaklığı (P21) Çerçevesinde yer alan öğrenme ve yenilikçilik becerilerine odaklanılmıştır. Bu kapsamda "yaratıcıllk ve yenilikçilik", "iletişim ve iş birliği", "eleştirel düşünme ve problem çözme" becerileri açıklanmıştır. Verilen bilgiler çeşitli şekiller, kavram haritaları ve etkinliklerle desteklenmiştir. Bunu yanı sıra dijital çağda oldukça değerli görülen "büyük veriyi anlama" ve "dijital okuryazarlık" becerilerine yer verilmiştir. Büyük veri dijital ortamların artışıyla birlikte daha öncesinde hiç olmadığı kadar hız kazanmıştır. Elde bulunan verilerin büyük çoğunluğu son yıllarda üretilmiş verilerdir. Bu durdurulamaz veri akışı sürecinde bireylerin verileri anlamlandırabilmesi, analiz edebilmesi, amaca ve bağlama uygun şekilde stratejik olarak kullanabilmesi büyük önem taşır. Öğrenme ve yenilikçilik becerilerinin büyük veri ile birlikte değerlendirilmesi gerektiği düşünülmüştür. Ayrıca hayatın birçok alanında olduğu gibi öğrenme ve öğretme alanlarının da dijitalleşmesi öğrenme ve yenilikçilik becerilerinde dijital okuryazarlı̆̆ın önemini göstermektedir. Bu sebeple öğrenme ve yenilikçilik becerileri dijital okuryazarlık ile de ilişkilendirilerek sunulmuştur.

Beşinci bölümde 21. Yüzyıl Öğrenme Ortaklığı (P21) Çerçevesi’nde bir başka beceri alanı olan bilgi, medya ve teknoloji becerileri ele alınmıştır. Bilgi, medya ve okuryazarlık kavramlarına ilişkin bilgi verilmiş; bilgi, medya ve teknoloji beceri alanında yer alan "bilgi okuryazarlı̆̆ı", "medya okuryazarlığı" ve "bilgi, iletişim ve teknoloji okuryazarlı̆̆ı" üzerinde durulmuştur. Bilgiyi üretim hızının ve bilgiye erişim yollarının katlanarak arttı̆̆ı bilgi çağında bireyler bilgiyi yalnızca edinmekten öte; analiz edebilmek, yorumlayabilmek, eleştirel bir bakış açışıyla değerlendirebilmek ve farklı alanlara transfer edebilmek için birtakım bilgi ve becerilere gereksinim duymaktadır. Bilgi okuryazarlığı, medya okuryazarlığı ve bilgi, iletişim ve teknoloji okuryazarlığı bireylerin öğrenme ve iletişim sürecinde aktif rol almasını sağlamaktadır. Bu bölümde okuryazarlıklar türleri, boyutları ve modelleriyle birlikte ele alınmış, 21. yüzyıl eğitimi açısından öneminin kavranmasına yönelik kazanımlar hedeflenmiştir.

Altıncı bölüm 21. yüzyıl becerilerinin dil eğitimiyle ilişkisine yönelik bir giriş niteliğindedir. Dil-kültür ilişkisi merkeze alınarak 21. yüzyılda dil eğitiminin sorunlarına çok yönlü ve eleştirel bir bakış açısıyla değinilmiştir. Eğitim bir kültürlenme süreci olarak tanımlanmış ve eğitime yönelik tartışmaların kültürden ve kültürle sıkı ilişki içerisinde bulunan dilden bağımsız yapılamayacağı görüşü savunulmuştur. Kültürün çok çeşitli işlevlerine ve boyutlarına yer verilse de konu dünden bugüne eğitim sürecinde etkili olduğu belirtilen kültürün iki işleviyle sınırlandırılmıştır: araçsal ve simgeleştirici işlev. Söz konusu işlevler dil ve kültür ilişkisi konusu özelinde detaylıca incelenmiştir. Ancak kısaca belirtmek gerekirse; araçsal işlevin kültürün maddi üretimlerini (teknoloji), simgeleştirici işlevin ise kültürün düşünsel üretimlerini (bilim, sanat, felsefe) yansıttı̆̆ı aktarılmaktadır. Dolayısıyla kültürün bir üretim süreci olduğu ve her iki işlevin de bu süreç sonunda ortaya çıkan ürünlerin niteliğinde etkili olduğu söylenebilir. Eğitimin güncel sorunlarına ve geleceğine de bu iki işlevin çatışması temelinde yaklaşılmıştır. Bu çatışmada kültürün araçsal işlevinin galip gelmesi ve bu durumun eğitim yaklaşımları tarafından da benimsenmesinin yol açtığı olumsuz sonuçlar konu alınır. Kültürün simgeleştirici işlevini, bir başka deyişle düşünce üretimini, destekleyecek nitelikte bir 21. yüzyll eğitimi düşüncesi vurgulanmıştır. Dilin, kültürün en önemli simgesel unsuru olduğunu düşünürsek dil eğitiminin bu süreçteki önemi yadsınamaz. Bu görüşlerden yola çıkarak genelde eğitim sistemine yönelik sorgulayıcı bir bakış açısıyla yaklaşılmasına, özelde Türkçe öğretmenlerinin dil eğitimi sürecinde dil ve düşünme becerilerini geliştirecek çalışmalara özen göstermesine yönelik önerilerde bulunulmuştur.

Yedinci bölümde 21. yüzyıl becerileri Türkçe Öğretim Programı açısından ele alınmıştır. Türkçe Öğretim Programı'nın öğrenmeöğretme yaklaşımı, amaçları, temaları, ölçme değerlendirme yaklaşımı ve programda yer alan dinleme, konuşma, okuma ve yazma kazanımları 21. yüzyıl becerileri bağlamında açıklanmıştır. Öğretim programları ve müfredatlar, eğitim hedeflerinin gerçekleştirilmesinde uygulamaya dönük bir anahtar niteliğindedir. Dolayısıyla öğretim programlarının yeniliğe açık, güncel çalışmalarla desteklenen ve bu doğrultuda sistemli bir şekilde dönüşebilen programlar olması gerekir. Bu kapsamda Millî Eğitim Bakanlığı tarafından belirlenmiş Türkiye Yeterlilikler Çerçevesi 21. yüzyıl becerilerini içermesi açısından önemli görülmüş, Türkiye Yeterlilik Çerçevesi ve içerdiği sekiz anahtar yetkinlik hakkında bilgi verilmiştir. Türkçe Öğretim Programı'ndaki temalarda yer verilen 21. yüzyıl becerileri ve becerilerin kazanımlara göre dağılımı incelenerek tablolar hâlinde sunulmuştur. 
Sekizinci bölüm 21. yüzyıl becerileri bağlamında ana dili eğitiminde anlama (dinleme ve okuma) becerilerine odaklanmaktadır. Okuma eğitimi bilgi okuryazarlığı, medya okuryazarlığı, bilgi ve iletişim teknolojileri okuryazarlığı, yaratıcılık ve eleştirel düşünme becerisi açısından; dinleme eğitimi ise yaratıcılık, eleştirel düşünme ve iletişim becerisi açısından ele alınmıştır. Bunun yanı sıra bir diğer 21. yüzyıl becerisi olan iş birliği becerisinin geliştirilmesi için okuma çalışmalarında öğrenciler arasında iş birlikli ortamlar oluşturacak strateji ve etkinlikler önerilmiştir. 21. yüzyıl becerilerinin Türkçe Öğretim Programı'nda ve Türkçe derslerindeki yeri ve önemine değinilmiştir. Bu doğrultuda Türkçe öğretmenlerinin ve öğrencilerin 21. yüzyll becerilerinin geliştirilmesinde yararlanabilecekleri okuma ve dinleme becerilerine ilişkin etkinlik örneklerine yer verilmiştir.

Dokuzuncu bölüm bir önceki bölümün devamı ve tamamlayıcısı olup ana dili eğitiminde anlatma (konuşma ve yazma) becerilerini 21. yüzyl becerileri bağlamında ele almaktadır. Öncelikle bir konuşmacının konuştuğu dile ait bilgisi kategoriler hâlinde incelenerek kavramsal bir çerçeve sunulur. Bu kısım bir konuşmacının bilmesi gereken dile ait ve dil dışı unsurları göstermektedir. Sonrasında 21. yüzyıl becerileri ile ilişkili konuşma yöntemleri ile ilgili bilgiler verilmiştir. Literatürden hareketle öğretmenlerin sözlü dil çalışmalarında yararlanabilecekleri yöntem önerilerinde bulunulmuştur. Ek olarak eğitimöğretim sürecinin en önemli bileşenlerinden olan ölçme ve değerlendirme aşaması vurgulanmış, konuşma eğitimi çalışmalarında süreç ve sonuç odaklı bir yaklaşımla kullanılabilecek ölçme araçlarına değinilmiştir. Yazma becerisinde ise ağırlıklı olarak 21. yüzyıl teknolojilerinin önemli bir getirisi olan dijital ortamlar ve bu ortamların yazma becerisi için sunmuş olduğu fırsatlar ele alınmıştır. Gelişen teknolojiyle artan dijital ortamlar sınıf içinde ve sınıf dışında yazma eylemini daha sık hâle getirmiştir. Dolayısıyla 21. yüzyıl bireylerinin yazmayı deneyimleyeceği, pratik yapabileceği ve dahası bu yolla dönütler alabileceği çok fazla sanal ortam bulunmaktadır. Yazma eğitiminde bu durumdan faydalanmak için geleneksel ve yenilikçi yaklaşımların sistemli bir şekilde bütünleştirilmesi görüşü savunulmuştur. Bu görüş doğrultusunda dijital medya ve yazma eğitimi birlikte ele alınarak "dönüt ve iş birliği", "yayın ve dağıtım", "çok modluluk", "örnekleme" ve "yeniden düzenleme" kavramları açıklanmıştır. Teknolojik gelişmeler birçok durumu değiştirip dönüştürse de bu kavramlar dijital medyanın kalıcı unsurları olarak görüldügünden üzerinde durulan kavramlar olmuştur. Konuşma eğitiminde olduğu gibi literatürden hareketle 21. yüzyıl becerilerine yönelik uygulanabilecek yazma yöntemlerine yer verilmiştir. Bunun yanı sıra yazılı bir metni değerlendirirken kullanılabilecek kategoriler tanımlanmış, verilen düzeltmelerde ortamın (sanal/kağıt üzerinde) yaratabileceği farklılıklara değinilmiştir.

Onuncu bölüm “21. Yüzyıl Becerileri Bağlamında Yabancı Dil Olarak Türkçe Öğretimi” başlığıyla okuyucuya sunulmuştur. 21. yüzyıl becerileri yalnızca ana dili bağlamında ele alınamayacak kadar geniş ve kapsamlı bir içeriğe sahiptir. Yabancı dil öğretimi de ana dili eğitimi gibi dil ve düşünme becerilerine dönük bir çalışma gerektirir. Bu sebeple Türkçenin yabancı dil olarak öğretimi de bu çalışmanın kapsamına dâhil edilmiştir. Bu bölümde öğrenme ve yenilikçilik becerileri merkeze alınmış, Türkçenin yabancı dil olarak öğretiminde sırasıyla iletişim, iş birliği, yaratıcılık ve eleştirel düşünme becerisi açıklanmıştır. Salt dil becerileri odaklı bir dil öğretiminin çağdaş yaklaşımları yansıtmadığı belirtilmiştir. 21. yüzyıl becerileri dil becerileri ile desteklenerek geliştirilebilecek becerilerdendir. Bu yaklaşımla organize edilen bir yabancı dil öğretiminde gerçekleștirilen uygulamaların 21. yüzyıl becerilerinden öğrenme ve yenilikçilik becerilerinin geliştirilmesine hizmet etmesi kaçınılmazdır. Özetlemek gerekirse;

- Hedef dilde sınıf içinde ya da sınıf dışında çeşitli bağlamlardaki dil kullanımı iletişim becerisinin gelişimine,

- Hedef dilde grup çalışmalarıyla yapılan kelime öğretimine, öz yeterliliğin ve iletişim becerisinin geliştirilmesine yönelik çalışmalar iş birliği becerisinin gelişimine,

- Hedef dilde öğrenilenler aracılığıyla yeni anlamlar ve çağrışımlar üretme yaratıcılık becerisinin gelişimine,

- Hedef dilde bilgiler arası karşılaştırmalar yapma, bilgileri analiz etme, sentezleme ve değerlendirme çalışmaları eleştirel düşünme becerisinin gelişimine hizmet eder.

On birinci bölüm Türkçe eğitiminde 21. yüzyıl becerilerinin ölçme ve değerlendirme sürecini temel alır. 21. yüzyıl becerilerinin ölçülmesinde kullanılabilecek yöntemlerin kavranması ve bu yöntemlere özgü etkinlikler oluşturulması gibi ölçme ve değerlendirme aşamasına dönük kazanımlar hedeflenmiştir. Bu hedef doğrultusunda bölüm, 21. yüzyıl becerilerinin ölçülmesi sürecinde kullanılabilecek ölçme araçları ve etkinlik örnekleri olmak üzere iki alt bölüme ayrılmıştır. Öncelikle 21. yüzyıl becerilerinin ölçülmesi sürecinde kullanılabilecek ölçme araçlarına ilişkin kısımda aşağıdaki ölçme araçları tanıtılmıştır:

- Performans değerlendirme süreçleri

- Derecelendirme ölçekleri

- Dereceli puanlama anahtarları

- Portfolyolar

- Geleneksel madde türü içeren araçlar

- Biodatlar

- Durumsal yargi testleri 
Sonrasında bu ölçme araçlarının etkinliklerde kullanımına yönelik örnekler sunulmuştur. Etkinlik örnekleri dört temel beceri alanına (okuma, yazma, dinleme ve konuşma) yönelik olarak tasarlanmıştır. Etkinlik planlamasında sınıf düzeyine ve etkinlik için gerekli materyallere, etkinlik öncesinde ve esnasında uygulanacak adımlara yer verilmiştir. Etkinlik sürecinde uygulanacak adımlar çeşitli strateji ve tekniklerle, Türkçe Öğretim Programı'ndaki kazanımlarla ilişkilendirilerek sunulmuştur. Kazanımların 21. yüzyll becerileri ile ilişkisi vurgulanmıştır. Son olarak tasarlanan etkinliklerin ölçme ve değerlendirme sürecinde yararlanılabilecek ölçme araçları eklenmiştir. Bölümde yer verilen etkinlik örnekleri, teorik bilgilerin uygulamadaki somut gösterimi açısından önemli görülmüştür.

On ikinci bölümde, bir önceki bölümde verilen etkinlik örneklerinden sonra, Türkçe eğitimi ve öğretiminde materyal ve etkinlik tasarlama-uygulama süreci ele alınır. 21. yüzyıl becerilerinin kazandırılması ve geliştirilmesi noktasında tasarlanan materyal ve etkinlikler sürecin daha verimli geçmesini ve çıktının daha nitelikli olmasını sağlayacaktır. Türkçe öğretmeni, hedeflenen kazanımlar doğrultusunda özgün, yaratıcı ve amaca uygun içerikler üretebilecek teorik ve uygulamaya dönük yeterliliğe sahip olmalıdır. Bu yeterlilik materyal ve etkinlik tasarımının ilkelerini ve boyutlarını, ilgili öğretim programı konusundaki yetkinliği gerektirir. Giriş bölümünde materyal tasarımı ilkelerine, materyal hazırlarken dikkat edilmesi gereken unsurlara ve materyal tasarımı sürecinin boyutlarına dair bilgi verilmiştir. P21 Çerçevesi merkez alınarak bu çerçevede tanımlanmış olan 21. yüzyıl becerilerinin gelişimini destekleyecek nitelikte etkinlik tasarımları önerilmiştir.

21. yüzyll becerileri bağlamında Türkçe eğitiminin; beceri alanlarından alt disiplinlerine, materyal ve etkinlik tasarımından ölçme değerlendirme sürecine kadar bütüncül ve kapsamlı bir şekilde ele alındığı bu kitabın alan yazınına katkı sağlayacağı düşünülmektedir. Eser hem Türkçe öğretmenleri hem de Türkçe öğretmeni adaylarının yararlanabileceği bir kaynak niteliğindedir.

\section{KAYNAKÇA}

MEB. (2019). Türkçe dersi öğretim programı (ilkokul ve ortaokul 1, 2, 3, 4, 5, 6, 7 ve 8. sinıflar). Ankara.

Partnership for 21st Century Skills (P21). (2019). Framework for 21st century learning. http://static.battelleforkids.org/documents/p21/P21_Framework_DefinitonsBK.pdf adresinden erişilmiştir.

Ural, Ş. (2003). Dil ve düşünce ilişkisinin mantıkla olan bağıntısına kısa bir bakış. Yediyıldız, B. (Ed.), Dil, kültür ve çağdaşlaşma (s. 29-37) içinde. Ankara: Hacettepe Üniversitesi Atatürk İlkeleri ve İnkılap Tarihi Enstitüsü.

Voogt J., \& Pareja Roblin N. (2010). 21st century skills. Enschede: University of Twente. 